\title{
Statistical Modeling of Morphological Parameters of Barchan Dunes (Case Study: Chah Jam Erg in South of Haj Ali GHoli Playa, in Central Part of Semnan Province, IRAN)
}

Seyed Hojjat Mousavi (Corresponding author)

M.A of geomorphology at Isfahan University

Azadi Sq., Isfahan City, IRAN

Tel: 9891-9670-2813Ｅ-mail: hojjat.mousavi.2006@Gmail.com

Mahmoud Dorgouie

M.A of geomorphology at Isfahan University

Department of Geography, Humanities College, Isfahan University

Azadi Sq., Isfahan City, IRAN

Tel: 9891-7376-5175_E-mail: M.dorgouie2008@yahoo.com

Abbas Ali Vali

Assistant professor of Range and Watershed department, Shiraz University Natural Resources College, Shiraz University, Gas Sq., Shiraz City, IRAN

Tel: 9891-3108-9607 E-mail: vali@shirazu.ac.ir

Mohsen Pourkhosravani

PHD Student in geography department of Isfahan University.

Department of Geography, Humanities College, Isfahan University, Azadi Sq., Isfahan City, IRAN

Tel: 9891-3347-0729 E-mail: mohsen_Pourkhosravani_2007@yahoo.com

Ali Reza Arab Ameri

M.A student of geomorphology at Isfahan University

Department of Geography, Humanities College, Isfahan University, Azadi Sq., Isfahan City, IRAN

Tel: 9891-9173-5198_E-mail: alireza.ameri91@yahoo.com

\begin{abstract}
A wide variety of aeolian sand dunes are found in Chah Jam erg, in central part of IRAN, best known type of them are the barchan dunes, shaped in a crescent, which occur if the wind comes steadily from the same direction throughout the year and if there is not enough sand to cover the entire surface. Barchan dunes in studied area are moving to $20 \mathrm{~m} /$ year toward S-SW. Their speed is dependent on wind velocity, three dimensional morphology and interaction between them. In this study, morphological parameters of barchan dunes and their annual movement rate (from 1/4/2008 to 1/4/2009) have been measured. Then using regression analysis method, type and intensity of relationship between morphological parameters and movement rate have been reexamined. These relationships follow simple and multivariable liner, power and exponential relations. Finally, we represented the models, by using them, can easily assess annual movement rate of Barchan dunes.
\end{abstract}

Keywords: Barchan, Chah Jam erg, Regression analysis, Morphological parameters

\section{Introduction}

At present, 65 percentage of Iran plateau is being located in arid and semiarid climate, and dry regions with Aeolian sand dunes and sparse vegetation are covering million 80 hectares from its area. Mobile sand dunes occupy million 12 hectares from this extent, approximately (Refahi, 2004). Barchan dunes are one of the most 
abundant and the most common Aeolian compressive forms that originate from reciprocal interaction between wind flow and sand bed (Hersen, 2004). These features depend mainly on the amount of available sand and on the change in the direction of the wind over the year (Bagnold, 1941; Brookfield and Ahlbrandt, 1983; Nickling, 1986; Kocurek, Pye and Tsoar, 1990; Besler, 1992; Lancaster, 1995; 1996; Sauermann et al, 2003). The main sitting of barchan dunes is situated between wind origin and principal site of concentration of erg (Mahmoudi, 2004).

Barchan's plan shape is a parabola-like curve reaching from the tip of one horn to the point of maximum slip face height and back to the tip of the other horn. The windward or stoss-side of the dune is limited by a sharp edge, called the brink. The brink coincides in many cases with the crest of the dune and separates the slip face from the dune's windward side (Sauermann et al, 2000).

A wide variety of barchan dunes are found in south part of Haj Ali GHoli playa, in central part of Semnan province, in IRAN. Barchan dunes of this area have been formed from quick sand, and with maintain of their crescent shape migrate along prevailing wind. Therefore displacement and lateral movements with annual typical trend is the most important of their characteristics. Barchans movements and displacement has been a natural threat and destructive factor for human infrastructure for a long time, that disregard is caused naught and mortuary of this infrastructure. Statistical analysis of barchans morphometric and morphodynamic parameters is effective in recognition of behavior and function of this feature in nature and realization of trend of its annual lateral movement. This achievement will be a useful help for researchers to decline hazards that are caused from barchans movement rate.

Unlike more widely studied desert dunes for which sediment transport dynamics have been documented in many field studies (Howard et al., 1978; Tsoar, 1983; Lancaster, 1989; Livingstone, 1993), only a few studies have documented the patterns of sediment transport across parabolic dunes, mainly in coastal settings (e.g., Robertson-Rintoul,1990; Arens et al., 2004). Research on the dynamics of parabolic dunes has focused on several key topics including: (i) dune distribution and morphology (Landsberg, 1956; Cooper, 1958; David, 1977, 1981; Pye, 1982; Anton and Vincent, 1986; Pye, 1993; Wolfe and David, 1997); (ii) timing of past dune activity (Wolfe et al., 1995; David et al., 1999; Wolfe et al., 2000, 2001; Arbogast et al., 2002; Forman and Pierson, 2003; Havholm and Running, 2005); (iii) rates of migration (Cooper, 1958; Pye, 1982; Anthonsen et al., 1996; David et al., 1999; Craig, 2000; Tsoar and Blumberg, 2002; Bailey and Bristow, 2004; Marín et al., 2005); (iv) internal structure (Bigarella, 1975; Halsey et al., 1990); and (v) contemporary processes (Robertson-Rintoul, 1990; Arens et al., 2004). Despite this progress, they do represent the best-studied type of dunes, and both their morphological and dynamic parameters are well understood (e.g. Bagnold, 1941; Hesp and Hastings, 1998) and have been successfully modeled on the individual dune scale (e.g. Herrmann and Sauermann, 2000; Hersen, 2004) as well as on the dune field scale (Lima et al., 2002). Besides their wide distribution in arid environments on Earth (e.g. India: Singhvi and Kar, 2004; Israel: Tsoar and Blumberg, 2002; Saudi Arabia: Al-Harthi, 2002; Abolkhair, 2004; Chad: Warren et al., 2007; North America: Forman et al., 2001) they have also been observed in submarine environments (Todd, 2005) and on Mars (Bourke et al., 2006). In the coastal desert of southern Peru, barchans have been investigated by Finkel (1959), Hastenrath (1967), Lettau and Lettau (1969) and Gay $(1962,1999)$. Empirical relationships between barchans width and height have been found by several authors and summarized by Hesp and Hastings (1998). Furthermore, an empirical relationship between barchans width and migration rate has been established for the Pampa de Jaguay barchans swarm and a further group of barchans (Gay, 1962, 1999).

In this paper, using quantity measurement methods and statistical modeling, relationships among morphometric and morphodynamic parameters of barchan dunes in Chah Jam erg are studied and realized. Also we have tried to describe morphology characterizes of the Barchan dunes using modeling process of mathematical and statistical methods. The aim of this study is the reorganization of alometric relationships among morphometric parameters and representation of statistical equations of estimate of barchans movement rate. In addition to, effect of each parameter over barchans movement rate is assessed. Using common methods of modeling, type and intensity of relationship and characteristics of models, such as constant coefficients, R square, STD error of estimate and rate have been investigated and represented in order to estimate alometric relationships among barchans morphological parameters. The obtained results will be very important for investigation of shape and recognition of behavior of Barchans dunes in nature. The recognition of morphological relationships between barchan parameters can act as an index in order to determine the condition of barchan system and also shed light on the its trends. Furthermore estimate of these parameters and recognition of their relationships is a consequence from rate of threat and disturbance and provide for environmental managers with the same, that 
their investigation determine different region from the view point of environmental management and prioritize them.

\section{Study area}

\subsection{Geographical position}

The studied field is located in south of Haj Ali Gholi playa, in central part of Semnan province, IRAN (Fig. 1). Haj Ali Gholi playa is the most important playa of Semnan province, that is situated in southwestern of Shahroud to south of Damghan. This playa is a tectonic and sediment hole, which at present is influenced by different geomorphic and climatic process. Shortage of vegetation cover and moisture are caused windy geomorphic process have been dominated upon other processes around of this playa. So, we can observe some kinds of windy features erosion in this region. Chah Jam erg, with extent about 25260 hectares, is one of the most important of ergs of Haj Ali Gholi playa that is located irregularly along northeastern - southwestern edge of playa with 10 to $12 \mathrm{~km}$ length (Ahmadi, 2007). Studied field (Chah Jam erg) is bounded between latitudes $35^{0}$, $45^{-}$to $35^{\ominus}, 50^{-} \mathrm{N}$ and between longitudes $54^{0}, 40^{-}$to $55^{\circ}, 10^{-} \mathrm{E}$ (Fig. 1).

\subsection{Climatic conditions}

The typical geographical position of studied area is caused opposite climatic conditions in different seasons of year. Furthermore, human and natural intensified factors of desertification are other reasons of opposite climatic conditions in this area. Position of field in south of Alborz chain mountain, vicinity with dry plains of Central Iran, remote from moisture masses, be influence of rainy masses, direction and length of chain mountains and locally dry winds are caused a arid climate for studied area (Table 1). Summer climate of this field is controlled by subtropical high-pressure, and its winter climate is controlled by western winds that originate from Mediterranean Sea. The prevailing wind direction in the study area is mainly from the E-NE with annual speed mean about 4.9 knots, although dusty winds occasionally come from the other direction (Fig. 2).

\section{Methods and techniques}

At first, studied area is recognized via satellite images of Google Earth, and then barchans morphological parameters are measured along 10 transects that were covering entire extent of Chah Jam erg. Measurements are based on fig. 3. This figure shows types of barchan morphological parameters and method of their measurement (Fig. 3).

We define for each barchan dunes, the lengths $\mathrm{L}_{\mathrm{a}}, \mathrm{L}_{\mathrm{b}}$ and the widths $\mathrm{W}_{\mathrm{a}}, \mathrm{W}_{\mathrm{b}}$ independently, as did Finkel (1959), Hesp and Hastings (1998), Sauermann et al (2000) and Daniell \& Hughes (2007). The orientation of the measuring axis is chosen according to the wind direction, which coincides with the symmetry line for a totally symmetric dune. Furthermore, this study introduces the length of the slip face $\mathrm{L}_{\mathrm{s}}$ and the length $\mathrm{L}_{\mathrm{o}}$ from the dune's toe on the windward side to the brink. Finally, the height of the slip face $\mathrm{H}$ is defined at the highest point of the brink, which is the intersection of the brink and the longitudinal centerline of the dune.

The total width (W) of a barchan is the sum of the widths $\mathrm{W}_{\mathrm{a}} \& \mathrm{~W}_{\mathrm{b}}$. The overall length ( $\mathrm{L}$ ) of a barchan is the sum of the length $\left(\mathrm{L}_{\mathrm{o}}\right)$ from the windward foot of the dune to its crest, the length of the slip face $\left(\mathrm{L}_{\mathrm{s}}\right)$, and the average of the horn lengths $\left[\left(\mathrm{L}_{\mathrm{a}}+\mathrm{L}_{\mathrm{b}}\right) / 2\right]$ as defined in Fig. 3 .

$$
\begin{array}{ll}
\text { Eq. (1): } & \mathrm{W}=\mathrm{W}_{\mathrm{a}}+\mathrm{W}_{\mathrm{b}} \\
\text { Eq. (2): } & \mathrm{L}=\mathrm{L}_{\mathrm{o}}+\mathrm{L}_{\mathrm{s}}+\left[\left(\mathrm{L}_{\mathrm{a}}+\mathrm{L}_{\mathrm{b}}\right) / 2\right]
\end{array}
$$

Barchan perimeter and area are measured according to Fig. 4, whereas at first a coordinate system is simulated for each barchan dunes in the nature, and then coordinates of 21 points over barchan perimeter is determined (Fig. 4). Pronounced points are planed on millimeteric paper with scale of 1:100, then barchan perimeter and area is measured by pelanymeter and curvimeter respectively as illustrated in Fig. 4.

Barchan dunes volume (V) is a function from height and area, and was calculated as a half pyramid volume using Eq. 3 for all dunes (Hersen et al., 2004; Hesse, 2008).

$$
\text { Eq. (3): } \quad \mathrm{V}=0.16666(\mathrm{~A} \times \mathrm{H})
$$

Where in this equation $\mathrm{A}$ is area and $\mathrm{H}$ is height of barchan dunes.

Movement rate of studied barchan dunes in this paper is measured via installation of a pique with $70 \mathrm{CM}$ height in dune's windward side foot and in annul time period from 1/4/2008 to 1/4/2009. At first, 15 key barchans in $1 / 4 / 2008$ date are recognized in field, and then a pique is installed in foot of dune's windward side for each barchan. For exact recognition of piques in next field investigations, their geographical position is record by GPS. 
Finally, studied barchans position proportionally to their piques is realized in $1 / 4 / 2009$ date and then movement rate of studied barchan dunes is measured directly in nature (Fig. 5).

Overall, then from measurement and determination of morphological parameters, for recognition of type and intensity of relationships between them, we have been studied and reexamined these relationships using SPSS software and regressive analysis technique. For this achievement, at start, we have been reexamined linear and nonlinear, simple and multiple variable regressive analysis technique such as linear, power, exponential, cubic, logarithmic, multiplier and etc, and then we have been selected the most important and the most suitable of relationships. Totally In this study, the most important and the most suitable of relationships are following from linear, power and exponential relationships. So, in the results part, only, these relationships are represented. Finally, for recognition of intensity of relationships, models parameters and value of $R, R$ square, adjusted $R$ square, std error of estimate and significant is reported also.

On this dune field, hundreds of barchans can be found; generally all of them have same size and shape (Fig. 6). The examined dunes are mainly of individual barchan type having heights between 1.2 and $17.9 \mathrm{~m}$, while their bases are typically 19.5 to307.9 $\mathrm{m}$ long and 6.3 to $165.6 \mathrm{~m}$ wide (Table 2).

\section{Results}

\subsection{Relationships between morphometric parameters}

Regression analysis was performed on the data obtained for morphometric parameters (Table 2). Equations representing the best-fit relationships were obtained using linear simple models. The respective equations were obtained at $95 \%$ confidence limits. The results of the regression models between the morphometric parameters of the investigated barchan dunes are listed in Table 3, and their graphical relationships are illustrated in Figs. 7.

Results of the statistical modeling using regression analysis method showed a maximum significant linear relationship height with length of Barchan dune with R square of 0.945 and STD error of estimate 0.889 .

\subsection{Relationships between plane geometric and morphometric parameters}

The results of the regression models between plane geometric and morphometric parameters of the investigated barchan dunes are reported in Table 4 and their graphical relationships are illustrated in Fig. 8.

The obtained Results of table 4 showed a maximum significant multiplier relationship of area with width and length of Barchan dunes with R square of 0.936 and STD error of estimate 0.321 . Also perimeter is modeled with sum of width and length by R square of 0.904 and STD error of estimate 0.431 .

\subsection{Relationships between volume and morphometric parameters}

Barchan dunes have been formed from quick sand, and migration and lateral movements is the most important of their characteristics. One of the most important factors for prediction of barchan behaviors is volume dunes, that it is useful for explaining its movement in spatial and temporal distributions and also this can act as an index in order to determine the condition of barchan system and shed light on the its trends. Furthermore recognition and estimate of this parameter is a consequence from rate of movement, threat and disturbance and provide for environmental managers with the same, that their investigation determines different regions from the view point of environmental management and prioritize them.

The results of the simple regression models between volume and morphometric parameters of the investigated barchan dunes are represented in Table 5, and their graphical relationships are illustrated in Figs. 9.

The obtained results of simple relationships between volume and morphometric parameters show a maximum significant power relationship with area of Barchan dunes with R square of 0.993 and std error of estimate 0.169.

The obtained results of the multi variable regression models between volume and morphometric parameters of the investigated barchan dunes are reported in Table 6.

\subsection{Relationships between movement rate and morphological parameters}

The obtained results of the regression models between movement rate and morphological parameters of the investigated barchan dunes are listed in Table 7, and their graphical relationships are represented in Figs. 10.

The obtained results show that relationships between movement rates and morphological parameters are following from simple linear, power and exponential relationships. The obtained relationships from relation study between this parameters represents a maximum significant exponential reverse relationships of movement rate with barchans height parameter with $\mathrm{R}$ square of 0.915 and std error of estimate of 0.133 . 
Relationships between movement rate and morphological parameters of barchan dunes of studied field illustrate significant linear, power and exponential reverse relationships of movement rate (Table 7 \& Fig. 10). Observations represent that barchan dunes of studied field can displace to $20 \mathrm{~m} /$ year. Barchan dunes in studied area move proportionally to the wind velocity and inversely proportionally to their height and $3 \mathrm{~d}$ shape. On the other ways, the less barchan $3 \mathrm{~d}$ morphology (volume and height), the more its annual movement rate. The higher the dune, the larger the amount of sand involved in its movement and, consequently, the slower its movement. So, in the same conditions, barchan dune, having shorter size, is migrated quickly.

\section{Discussion}

The base of applied geomorphology analysis is according to systemic stand point. Systemic geomorphology is based on recognition of geomorphic forms and processes and relationships between them. Efficiency of this stand point, when there are linear and nonlinear reciprocal relationships between parts and elements of system, is very important. The studied system in this research is Barchan landscape in the south of Haj Ali Gholi playa. Barchan dunes are open and natural systems and are capable of modeling in different levels.

A side view of a barchan shows a rather flat aerodynamic structure. When viewed from above, a barchan presents a crescent shape with two horns pointing downwind. A sharp edge divides the dune in two areas: the windward side and the slip face, where avalanches develop (Bagnold, 1941; Pye \& Tsoar, 1990; Cook et al, 1993). Because of a boundary layer separation along this sharp edge a large eddy develops downwind and wind speed decreases dramatically. Therefore, the incoming blown sand is dropped close to the brink line. That is why the barchan is known to be a very good sand trapper (Hersen, 2004). The source of sand transported by wind is the upwind flank of the dune. Part of this sand crosses the dune where the crest line makes a larger angle with the prevailing wind direction to form a slip-face on the downwind flank. This part is lifted again by the wind and moved along the downwind flank parallel to the crest line. The other part, striking the crest line at a smaller angle, does not cross the dune and moves along the upwind side, again, parallel to the crest line. The movement of the two parts tends to move the dune downwind along its crest line (Al-Harthi, 2002). Sometimes, when the drift of sand is too large, an avalanche occurs and grains are moved down the slip face. In short, grains are dragged by the wind from the windward side of the dune to the bottom of the slip face and, grain after grain, the dune moves (Hersen, 2004). So, the rate of sand drifting is a function of the sand grain size, the wind speed, and the geomorphic conditions.

Barchan dunes are highly mobile dunes which constitute a considerable threat to infrastructure in arid regions with sand. They move over roads, pipelines and cover even cities. The large time scales involved considerably complicate reliable measurements.

Field observations in this study show that barchan dunes can move to $20 \mathrm{~m} /$ year. Their speed is dependent on wind power and on their $3 \mathrm{~d}$ shape: for the same wind strength, the velocity of barchan is roughly inversely proportional to their height (Mousavi, 2009).

\section{Conclusion}

Interaction among climatic processes, obstacles of earth surface and Aeolian sediments characteristics are causes of creation of barchan dunes in study area. Barchan dunes have been forming from quick sand, and displacement and lateral movements is the most important of their characteristics. These features migrate along prevailing wind, while maintain their crescent shape and 3d morphology.

In this study, at first, Barchan morphological parameters have been defined and measured, and then type and intensity of relationships between them have been determined and modeled. The obtained result from study relations by regressive analysis technique show significant relationships among morphological parameters of barchan dunes of studied field. Also relationships between movement rate and morphological parameters illustrate significant linear, power and exponential reverse relationships. Observations represent that barchan dunes of studied field can displace to $20 \mathrm{~m} /$ year, and are moving proportionally to the wind velocity and inversely proportionally to their height and $3 \mathrm{~d}$ shape. On the other ways, the less barchan $3 \mathrm{~d}$ morphology (volume and height), the more its annual movement rate. Therefore, the higher size the dune, the larger the amount of sand involved in its movement and, consequently, the slower its movement. So, in the same climatic and geomorphic conditions, barchans dunes, having shorter size, is migrated quickly.

In this paper for modeling and conversion of morphometric relations of barchans parameters, we have been represented models statistically, that using them, we can easily account plane geometric parameters, deal of volume and annual movement rate of Barchan dunes. Therefore the results of this study provide possible of exact and rapid estimation of Barchan morphometric, plane geometric and morphdynamic parameters. 
The prevailing wind direction in the study area is mainly from the E-NE, so displacement direction of barchan dunes is mainly toward W- SW. These landscapes are mobile dunes which constitute a considerable threat to infrastructure in study field with their mobile sand. They move over communication ways of region, phone lines and even over Damghan city, and also disturb agricultural fields and intensify desertification problems in study area.

\section{References}

Ahmadi, H. (2004). Applied Geomorphology (Desert - Windy erosion). 2nd Volume, (3rd Ed.), Tehran: Tehran University Publication, (Chapter 3).

Al-Harthi, A. (2002). Geohazard assessment of sand dunes between Jeddah and Al-Lith, western Saudi Arabia. Journal of Environmental Geology, 42, 360-369.

Arbogast, A. F., Hansen, E. E. \& Van Oort, M. D. (2002). Reconstructing the geomorphic evolution of large coastal dunes along the southeastern shore of Lake Michigan. Journal of Geomorphology, 46, 241-255.

Abolkhair, Y. M. S. (2004). The statistical analysis of the sand grain size distribution of Al- Ubay-lah barchan dunes, northwestern Ar-Rub-Alkhali desert, Saudi Arabia. Journal of Geomorphology, 13, 103-109.

Anthonsen, K. L., Clemmensen, L. B. \& Jensen, J. H. (1996). Evolution of a dune from crescentic to parabolic form in response to short-term climatic changes - Rabjerg- Mile, Skagen-Odde, Denmark. Journal of Geomorphology, 17, 63-77.

Anton, D. \& Vincent, P. (1986). Parabolic dunes of the Jafurah Desert, Eastern Province, Saudi Arabia. Journal of Arid Environments, 11, 187-198.

Arens, S. M., Slings, Q. \& Vries, C. N. (2004). Mobility of a remobilized parabolic dune in Kennemerland, The Netherlands. Journal of Geomorphology, 59, 175-188.

Bagnold, R.A. (1941). The Physics of Blown Sand and Desert Dunes. London: Methuen.

Bailey, S. D. \& Bristow, C. S. (2004). Migration of parabolic dunes at Aberffraw, Anglesey, north Wales. Journal of Geomorphology, 59, 165-174.

Bigarella, J. J. (1975). Structures developed by dissipation of dune and beach ridge deposits. Journal of Catena, 2, 107-152.

Brook, F. J. (1999). Stratigraphy and landsnail faunas of Late Holocene coastal dunes, TokerauBeach, northern New Zealand. Journal of the Royal Society of New Zealand, 29, 337-359.

Craig, M. S. (2000). Aeolian sand transport at the Lanphere dunes, northern California. Journal of Earth Surface Processes and Landforms, 25, 239-253.

Cooper, W. S. (1958). Coastal Sand Dunes of Oregon and Washington. Journal of Geological Society of America Memoir, 72-89.

Daniell, J. \& Hughes, M. (2007). The morphology of barchan-shaped sand banks from western Torres Strait, northern Australia. Journal of Sedimentary Geology, 202, 638-652.

David, P. P. (1981). Stabilized dune ridges in northern Saskatchewan. Canadian Journal of Earth Sciences, 18, 286-310.

Finkel, H.J. (1959). The barchans of southern Peru. Journal of Geology, 67, 614-647.

Forman, S. L. \& Pierson, J. (2003). Formation of linear and parabolic dunes on the eastern Snake River Plain, Idaho in the nineteenth century. Journal of Geomorphology, 56, 189-200.

Gay, S. P. (1999). Observations regarding the movement of barchan sand dunes in the Nazca to Tanaca area of southern Peru. Journal of Geomorphology, 27, 279-293.

Halsey, L. A., Catto, N. R. \& Rutter, N. W. (1990). Sediment logy and development of parabolic dunes, Grande Prairie dune field, Alberta. Canadian Journal of Earth Science, 27, 1762-1772.

Hastenrath, S. (1967). The barchans of the Arequipa Region, Southern Peru. Journal of Geomorphology, 11, 300-331.

Havholm, K. G. \& Running, IV, G. L. (2005). Stratigraphy, sediment logy and environmental significance of late mid-Holocene dunes, Lauder Sand Hills, glacial lake Hind Basin, southwestern Manitoba. Canadian Journal of Earth Sciences, 42, 847-863.

Herrmann, H. J. \& Sauerman, G. (2000). The shape of dunes. Journal of Physical A, 283, 24-30. 
Hersen, P. (2004). On the crescentic shape of barchan dunes. The European Physical Journal B, 37, 507-514.

Hesp, P. \& Hastings, K. (1998). Width, height and slope relationships and aerodynamic maintenance of barchans. Journal of Geomorphology, 22, 193-204.

Hesse, R. (2008). Do swarms of migrating barchan dunes record pale environmental changes? - A case study spanning the middle to late Holocene in the Pampa de Jaguay, southern Peru. Journal of Geomorphology, 47, 1 6.

Hesse, P. P. \& Simpson, R. L. (2006). Variable vegetation cover and episodic sand movement on longitudinal desert sand dunes. Journal of Geomorphology, 81, 276-291.

Howard, A. D., Morton, J. B., Gad-el-Hak, M. \& Pierce, D. B. (1978). Sand transport model of barchan dune equilibrium. Journal of Sediment logy, 25, 307-338.

Hugenholtz, C.H., et al. (2008). Spatial and temporal patterns of aeolian sediment transport on an inland parabolic dune, Bigstick Sand Hills, Saskatchewan, Canada. Journal of Geomorphology, 77, $1-13$.

Kocurek, G., Townsley, M., Yeh, E., Havholm, K. \& Sweet, M. L. (1992). Dune and Dune-Field Development on Pardre Island, Texas, with Implocations for Interdune Deposition and Water-Table-Controlled Accumulation. Journal of Sediment. Petrol, 62, 622-635.

Lancaster, N. (1994). Dune morphology and dynamics. In: Abra- hams, Parsons_Eds.., Geomorphology of Desert Environments. Chapman \& Hall, London, Pp. 474-505.

Landsberg, S. Y. (1956). The orientation of dunes in Britain and Denmark in relation to wind. Geographical Journal, 122, 176-189.

Langbein, W. B. \& Leonold, L. B. (1964). Quasi-equilibrium states in channel morphology. Am. L. Sci, 262, 782-794.

Lettau, K. \& Lettau, H. (1969). Bulk transport of sand by the barchans of the Pampa de La Joya in Southern Peru. Zeitschrift fur Geomorphology, N.F., 13- 2, 182- 195.

Livingstone, I., Wiggs, G. F. S. \& Baddock, M. (2005). Barchan dunes: why they cannot be treated as 'solitons' or 'solitary waves'. Journal of Earth Surface Processes and Landforms, 30, 255-257.

Livingstone, I. (1993). A decade of surface change on a Namib linear dune. Journal of Earth Surface Processes and Landforms, 18, 661-664.

Lima, A. R., Sauermann, G., Herrmann, H. J. \& Kroy K. (2002). Modeling a dune field. Journal of Physical A, $310,487-500$.

Mahmoudi, F. A. (2003). Dynamic Geomorphology. Tehran-Iran. Payame Nour University Publication. 6th Ed., Pp. 73-97.

Mousavi, H. (2009). The assessment of effectiveness Barchan morphometry on stabilities (Case study: Erg Chah Jam). M.A. Thesis. Isfahan-Iran. University of Isfahan.

Marín, L., Forman, S. L., Valdez, A. \& Bunch, F. (2005). Twentieth century dune migration at the Great Sand Dunes National Park and Preserve, Colorado, relation to drought variability, Journal of Geomorphology, 70, $163-183$.

Nickling, W. G. (1986). Aeolian Geomorphology. Allen and Unwin. London.

Pye, K. (1982). Morphological development of coastal dunes in a humid tropical environment, Cape Bedford and Cape Flattery, north Queensland. Geografiska Annaler, 64A, 213-227.

Pye, K. \& Tsoar, H. (1990). Aeolian Sand and Sand Dunes. Unwin Hyman. London.

Refahi, H. (2004). Windy erosion and its control. Tehran-Iran. Tehran University Publication. 3rd edition, (Chapter 1).

Sauermann, G., Rognon, P., Poliakov, A. \& Herrmann, H. J. (2000). The shape of the barchan dunes of Southern Morocco. Journal of Geomorphology, 36, 47-62.

Sauermann, G., Andrade, J. S., Maia, L. P., Costa, U. M. S., Araujo, A. D., \& Herrmann, H. J., (2003). Wind velocity and sand transport on a barchan dune. Journal of Geomorphology, 54, $245-255$.

Sørensen, M. (1991). An analytic model of wind-blown sand transport, Acta Mech. Suppl, 1, 67-81. 
Singhvi, A. K., \& Kar, A. (2004). The aeolian sedimentation record of the Thar Desert. Proceedings of the Indian Academy of Sciences, Journal of Earth and Planetary Sciences, 113, 371-401.

Tsoar, H., \& Blumberg, D. G. (2002). Formation of parabolic dunes from barchan and transverse dunes along Israel's Mediterranean coast. Journal of Earth Surface Processes and Landforms, 27, 1147-1161.

Valle, H. F. del., Rostagon, F. R, C. M., Coronato, F. R., Bouza, P. J., \& Blanceo, P. D. (2008). Sand dune activity in north-eastern Patagonia. Journal of arid Environment, 72, 411-422.

Wang, Z. T., Chen Tao, S., Wen Xie, Y., \& Hui Dong, G. (2007). Barchans of Minqin: Morphometry. Journal of Geomorphology, 89, 405-411.

Warren, A., Chappell, A., Todd, M. C., Bristow, C., Drake, N., Engelstaedter, S., Martins, V., M'bainayel, S., \& Washington, R. (2007). Dust-raising in the dustiest place on earth. Journal of Geomorphology, 92, 25-37.

Wolfe, S. A., Huntley, D. J., \& Ollerhead, J. (1995). Recent and late Holocene sand dune activity in southwestern Saskatchewan. Current Research 1995-B. Geological Survey of Canada, pp. 131-140.

Wolfe, S. A., Muhs, D. R., David, P. P., \& McGeehin, J. P. (2000). Chronology and geochemistry of late Holocene eolian deposits in the Brandon Sand Hills, Manitoba, Canada. Journal of Quaternary International, 67, 61-74.

Wolfe, S. A., Huntley, D. J., David, P. P., Ollerhead, J., Sauchyn, D. J., \& MacDonald, G. M. (2001). Late 18th century drought-induced sand dune activity, Great Sand Hills, Saskatchewan. Canadian Journal of Earth Science, 38, 105-117.

Table 1. Values of climatic elements of study area (average of 30 years period from 1978 to 2008)

\begin{tabular}{lccccc}
\hline Elements & Winter & Spring & Summer & Autumn & Annual \\
\hline Average of minimum temperature in C & -0.75 & 14.56 & 19.98 & 3.53 & 9.32 \\
\hline Average of maximum temperature in C & 13.73 & 32.54 & 39.02 & 20.01 & 26.34 \\
\hline Average of minimum relative humidity in percent & 41.01 & 26.33 & 29.81 & 37.73 & 32.33 \\
\hline Average of maximum relative humidity in percent & 65.03 & 42.10 & 43.66 & 55.42 & 50.49 \\
\hline Average of precipitation in mm & 56.16 & 20.76 & 2.55 & 16.33 & 85.81 \\
\hline Average of wind speed in knot & 3.3 & 6.3 & 7.5 & 2.5 & 4.95 \\
\hline
\end{tabular}

Table 2. Descriptive statistic characteristics of barchan dunes in study area

\begin{tabular}{ccccccc}
\hline Parameter* & Range & Minimum & Maximum & Average & $\begin{array}{c}\text { Standard } \\
\text { Deviation }\end{array}$ & Skewness \\
\hline $\mathrm{H}$ & 16.7 & 1.2 & 17.9 & 5.802 & 3.768 & 1.244 \\
\hline $\mathrm{W}_{\mathrm{a}}$ & 86 & 3.1 & 89.1 & 27.311 & 17.658 & 1.195 \\
\hline $\mathrm{W}_{\mathrm{b}}$ & 61.4 & 3.2 & 94.6 & 32.796 & 21.672 & 1.051 \\
\hline $\mathrm{W}$ & 159.3 & 6.3 & 165.6 & 60.107 & 37.93 & 0.966 \\
\hline $\mathrm{L}_{\mathrm{a}}$ & 76.3 & 4.2 & 80.5 & 29.498 & 20.191 & 0.103 \\
\hline $\mathrm{L}_{\mathrm{b}}$ & 87.8 & 1.5 & 89.3 & 35.573 & 22.673 & 0.728 \\
\hline $\mathrm{L}_{\mathrm{o}}$ & 214.5 & 9.1 & 223.6 & 52.467 & 42.761 & 1.727 \\
\hline $\mathrm{L}_{\mathrm{s}}$ & 37.9 & 1.5 & 39.4 & 9.667 & 7.361 & 1.647 \\
\hline $\mathrm{L}$ & 288.8 & 19.5 & 307.85 & 94.67 & 65.141 & 1.134 \\
\hline $\mathrm{V}$ & $6.44 \mathrm{E} 4$ & 7.94 & 64379.3 & $7.8524 \mathrm{E} 3$ & 12808.6 & 2.539 \\
\hline $\mathrm{P}$ & $2.99 \mathrm{E} 4$ & 81.2 & 30824.51 & $5.0813 \mathrm{E} 3$ & 5907.21 & 2.121 \\
\hline $\mathrm{A}$ & $9.25 \mathrm{E} 4$ & 75.15 & 1038.15 & $3.2725 \mathrm{E} 3$ & 206.571 & 1.243 \\
\hline $\mathrm{D}$ & 14.5 & 2.3 & 16.8 & 9.946 & 3.75 & -0.143 \\
\hline
\end{tabular}

*. Length, height, width, perimeter and movement are given in $\mathrm{m}$ and area and volume are given in $\mathrm{m}^{2}$ and $\mathrm{m}^{3}$, respectively 
Table 3. Results and summary of different regression models fitted to morphometric parameters of studied barchan dunes

\begin{tabular}{ccccccc}
\hline Parameter & $\begin{array}{c}\text { Type } \\
\text { of } \\
\text { relation }\end{array}$ & $\mathrm{R}$ & $\mathrm{R}^{2 * *}$ & $\begin{array}{c}\text { Adjusted } \\
\mathrm{R} 2\end{array}$ & $\begin{array}{c}\text { Std error } \\
\text { of } \\
\text { estimate }\end{array}$ & Equation \\
\hline L \& W & Linear & 0.869 & 0.755 & 0.750 & 18.952 & $\mathrm{~W}=0.506 \mathrm{~L}+12.203$ \\
\hline L \& H & Linear & 0.972 & 0.945 & 0.944 & 0.889 & $\mathrm{H}=0.056 \mathrm{~L}+0.477$ \\
\hline W \& H & Linear & 0.863 & 0.744 & 0.739 & 19.24 & $\mathrm{H}=0.086 \mathrm{~W}+0.65$ \\
\hline
\end{tabular}

$*^{*} \alpha \leq 0.01$

Table 4. Results and summary of different regression models fitted to plane geometric and morphometric parameters of studied barchan dunes

\begin{tabular}{ccccccc}
\hline Parameter & $\begin{array}{c}\text { Type of } \\
\text { relation }\end{array}$ & $\mathrm{R}$ & $\mathrm{R}^{2 * *}$ & $\begin{array}{c}\text { Adjusted } \\
\mathrm{R} 2\end{array}$ & $\begin{array}{c}\text { Std error of } \\
\text { estimate }\end{array}$ & Equation \\
\hline W \& A & Power & 0.959 & 0.921 & 0.919 & 0.356 & $\mathrm{~A}=2.734 \mathrm{~W}^{1.768}$ \\
\hline L \& A & Power & 0.928 & 0.861 & 0.858 & 0.471 & $\mathrm{~A}=1.941 \mathrm{~L}$ 1.671 \\
\hline W \& L with A & Multiplier & 0.981 & 0.936 & 0.962 & 0.321 & $\mathrm{~A}=0.631(\mathrm{~W} \times \mathrm{L})$ \\
\hline W \& P & Linear & 0.919 & 0.845 & 0.842 & 0.783 & $\mathrm{P}=5.006 \mathrm{~W}+26.364$ \\
\hline L \& P & Linear & 0.923 & 0.851 & 0.848 & 0.522 & $\mathrm{P}=2.925 \mathrm{~L}+50.304$ \\
\hline W \& L with P & Sum & 0.957 & 0.904 & 0.902 & 0.431 & $\mathrm{P}=2.071(\mathrm{~L}+\mathrm{W})$ \\
\hline
\end{tabular}

$* *-\alpha \leq 0.01$

Table 5. Results and summary of different regression models fitted to volume and morphometric parameters of studied barchan dunes

\begin{tabular}{ccccccc}
\hline Parameter & $\begin{array}{c}\text { Type of } \\
\text { relation }\end{array}$ & $\mathrm{R}$ & $\mathrm{R}^{2 * *}$ & $\begin{array}{c}\text { Adjusted } \\
\mathrm{R} 2\end{array}$ & $\begin{array}{c}\text { Std error } \\
\text { of estimate }\end{array}$ & Equation \\
\hline $\mathrm{W} \& \mathrm{~V}$ & Power & 0.962 & 0.924 & 0.923 & 0.538 & $\mathrm{~V}=0.042 \mathrm{~W}^{2.748}$ \\
\hline $\mathrm{L} \& \mathrm{~V}$ & Power & 0.974 & 0.949 & 0.948 & 0.445 & $\mathrm{~V}=0.015 \mathrm{~L}^{2.72}$ \\
\hline $\mathrm{H} \& \mathrm{~V}$ & Power & 0.983 & 0.966 & 0.965 & 0.363 & $\mathrm{~V}=15.177 \mathrm{H}^{3.067}$ \\
\hline $\mathrm{A} \& \mathrm{~V}$ & Power & 0.996 & 0.993 & 0.992 & 0.169 & $\mathrm{~V}=0.025 \mathrm{~A}^{1.449}$ \\
\hline $\mathrm{P} \& \mathrm{~V}$ & Power & 0.976 & 0.953 & 0.952 & 0.425 & $\mathrm{~V}=0.000243 \mathrm{P}^{2.855}$ \\
\hline
\end{tabular}

$*_{-} \alpha \leq 0.01$ 
Table 6. The obtained results from multivariable regression models between volume and morphometric parameters of barchans

\begin{tabular}{|c|c|c|c|}
\hline Parameter & $\mathrm{R}^{2 * *}$ & $\begin{array}{c}\text { Constant } \\
\text { coefficient }\left(b_{0}\right)\end{array}$ & Equation \\
\hline \multirow{3}{*}{ W \& L with V } & 0.876 & 1.299 & $\mathrm{~V}=\mathrm{b}_{0}(\mathrm{~W} \times \mathrm{L})$ \\
\hline & 0.887 & 0.01 & $\mathrm{~V}=\mathrm{b}_{0}\left(\mathrm{~W}^{2} \times \mathrm{L}\right)$ \\
\hline & 0.995 & 0.006 & $\mathrm{~V}=\mathrm{b}_{0}\left(\mathrm{~W} \times \mathrm{L}^{2}\right)$ \\
\hline \multirow[t]{3}{*}{ W \& H with V } & 0.871 & 21.897 & $\mathrm{~V}=\mathrm{b}_{0}(\mathrm{~W} \times \mathrm{H})$ \\
\hline & 0.912 & 1.79 & $\mathrm{~V}=\mathrm{b}_{0}\left(\mathrm{~W}^{2} \times \mathrm{H}\right)$ \\
\hline & 0.994 & 1.772 & $\mathrm{~V}=\mathrm{b}_{0}\left(\mathrm{~W} \times \mathrm{H}^{2}\right)$ \\
\hline \multirow[t]{3}{*}{ W \& A with V } & 0.887 & 0.016 & $\mathrm{~V}=\mathrm{b}_{0}(\mathrm{~W} \times \mathrm{A})$ \\
\hline & 0.795 & $0.01 \times 10^{-9}$ & $\mathrm{~V}=\mathrm{b}_{0}\left(\mathrm{~W}^{2} \times \mathrm{A}\right)$ \\
\hline & 0.839 & $7.55 \times 10^{-7}$ & $\mathrm{~V}=\mathrm{b}_{0}\left(\mathrm{~W} \times \mathrm{A}^{2}\right)$ \\
\hline \multirow{3}{*}{ A \& L with $V$} & 0.995 & 0.01 & $\mathrm{~V}=\mathrm{b}_{0}(\mathrm{~A} \times \mathrm{L})$ \\
\hline & 0.833 & $3.99 \times 10^{-7}$ & $\mathrm{~V}=\mathrm{b}_{0}\left(\mathrm{~A}^{2} \times \mathrm{L}\right)$ \\
\hline & 0.915 & $3.66 \times 10^{-5}$ & $\mathrm{~V}=\mathrm{b}_{0}\left(\mathrm{~A} \times \mathrm{L}^{2}\right)$ \\
\hline \multirow[t]{3}{*}{ H \& A with V } & 0.999 & 0.77 & $\mathrm{~V}=\mathrm{b}_{0}(\mathrm{H} \times \mathrm{A})$ \\
\hline & 0.926 & 0.011 & $\mathrm{~V}=\mathrm{b}_{0}\left(\mathrm{H}^{2} \times \mathrm{A}\right)$ \\
\hline & 0.843 & $6.9 \times 10^{-6}$ & $\mathrm{~V}=\mathrm{b}_{0}\left(\mathrm{H} \times \mathrm{A}^{2}\right)$ \\
\hline \multirow[t]{3}{*}{ L \& H with V } & 0.917 & 12.312 & $\mathrm{~V}=\mathrm{b}_{0}(\mathrm{~L} \times \mathrm{H})$ \\
\hline & 0.945 & 0.052 & $\mathrm{~V}=\mathrm{b}_{0}\left(\mathrm{~L}^{2} \times \mathrm{H}\right)$ \\
\hline & 0.935 & 0.875 & $\mathrm{~V}=\mathrm{b}_{0}\left(\mathrm{~L} \times \mathrm{H}^{2}\right)$ \\
\hline
\end{tabular}

$*_{-} \alpha \leq 0.01$

Table 7. Results and summary of different regression models fitted to movement rate and morphological parameters of studied barchan dunes

\begin{tabular}{|c|c|c|c|c|c|c|}
\hline Parameter & $\begin{array}{ll}\begin{array}{l}\text { Type } \\
\text { relation }\end{array} & \text { of } \\
\end{array}$ & $\mathrm{R}$ & $\mathrm{R}^{2 * *}$ & $\begin{array}{l}\text { Adjusted } \\
\text { R2 }\end{array}$ & $\begin{array}{c}\text { Std error } \\
\text { of estimate }\end{array}$ & Equation \\
\hline \multirow[t]{3}{*}{ H \& D } & Linear & 0.903 & 0.816 & 0.813 & 1.621 & $\mathrm{D}=-0.899 \mathrm{H}+15.165$ \\
\hline & Power & 0.921 & 0.848 & 0.845 & 0.178 & $\mathrm{D}=26.168 \mathrm{H}^{-0.673}$ \\
\hline & Exponential & 0.956 & 0.915 & 0.913 & 0.133 & $\mathrm{D}=17.786 \mathrm{e}^{-0.115 \mathrm{H}}$ \\
\hline \multirow[t]{3}{*}{$\mathrm{W} \& \mathrm{D}$} & Linear & 0.854 & 0.730 & 0.724 & 1.967 & $\mathrm{D}=-0.084 \mathrm{~W}+15.025$ \\
\hline & Power & 0.822 & 0.676 & 0.669 & 0.261 & $\mathrm{D}=77.46 \mathrm{~W}^{-0.55}$ \\
\hline & Exponential & 0.853 & 0.729 & 0.723 & 0.238 & $\mathrm{D}=16.843 \mathrm{e}^{-0.01 \mathrm{~W}}$ \\
\hline \multirow[t]{3}{*}{ L \& D } & Linear & 0.878 & 0.771 & 0.776 & 1.812 & $\mathrm{D}=-0.05 \mathrm{~L}+14.732$ \\
\hline & Power & 0.867 & 0.751 & 0.746 & 0.228 & $\mathrm{D}=105.533 \mathrm{~L}^{-0.566}$ \\
\hline & Exponential & 0.932 & 0.869 & 0.866 & 0.165 & $\mathrm{D}=16.858 \mathrm{e}^{-0.006 \mathrm{~L}}$ \\
\hline \multirow[t]{3}{*}{$\mathrm{P} \& \mathrm{D}$} & Linear & 0.897 & 0.804 & 0.800 & 1.673 & $D=-0.016 P+15.16$ \\
\hline & Power & 0.867 & 0.767 & 0.762 & 0.221 & $\mathrm{D}=254.418 \mathrm{P}^{-0.598}$ \\
\hline & Exponential & 0.932 & 0.869 & 0.866 & 0.165 & $\mathrm{D}=17.559 \mathrm{e}^{-0.002 \mathrm{P}}$ \\
\hline \multirow[t]{3}{*}{$\mathrm{A} \& \mathrm{D}$} & Linear & 0.825 & 0.682 & 0.675 & 2.135 & $\mathrm{D}=-0.000522 \mathrm{~A}+12.513$ \\
\hline & Power & 0.869 & 0.756 & 0.751 & 0.226 & $\mathrm{D}=90.411 \mathrm{~A}^{-0.296}$ \\
\hline & Exponential & 0.899 & 0.809 & 0.805 & 0.200 & $\mathrm{D}=12.781 \mathrm{e}^{-6.881 \mathrm{~A}}$ \\
\hline \multirow[t]{3}{*}{ H \& D } & Linear & 0.842 & 0.709 & 0.703 & 2.042 & $\mathrm{D}=-0.000343 \mathrm{~V}+12.569$ \\
\hline & Power & 0.875 & 0.766 & 0.792 & 0.221 & $\mathrm{D}=99.721 \mathrm{~V}^{-0.292}$ \\
\hline & Exponential & 0.915 & 0.838 & 0.835 & 0.184 & $\mathrm{D}=12.869 \mathrm{e}^{-4.511 \mathrm{~V}}$ \\
\hline
\end{tabular}

$* *-\alpha \leq 0.01$ 


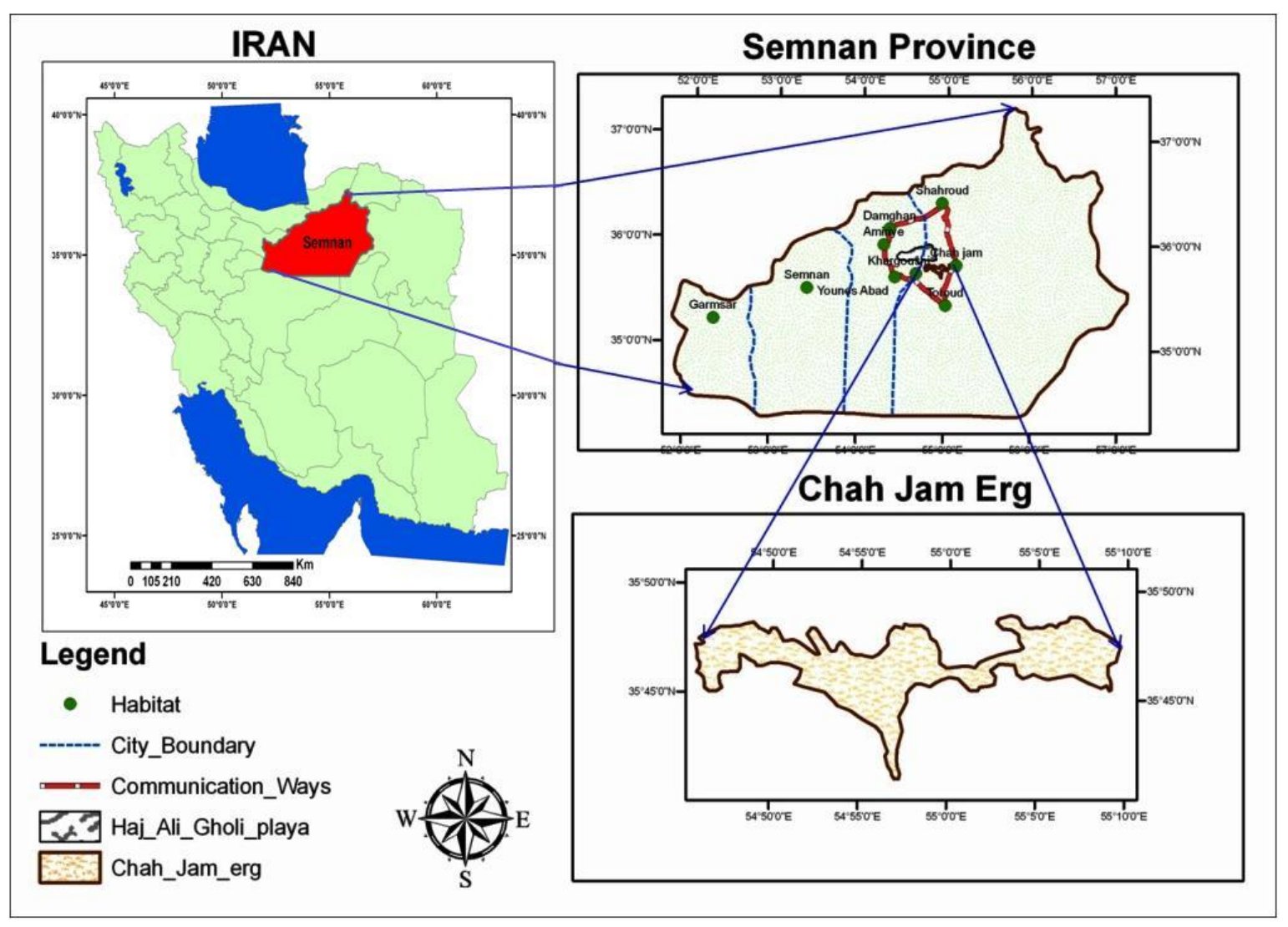

Figure 1. Geographical position of Chah Jam erg

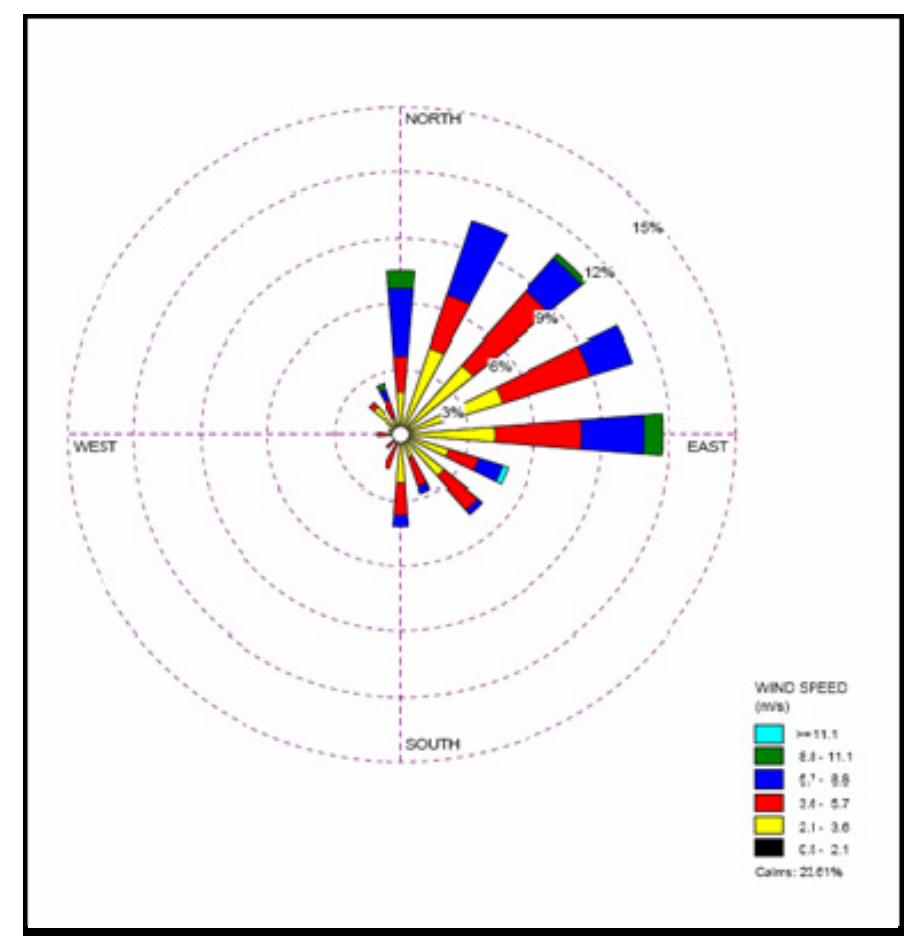

Figure 2. Wind rose of Damghan, in north of Chah Jam erg (from 2001 to 2007, after May 2008 


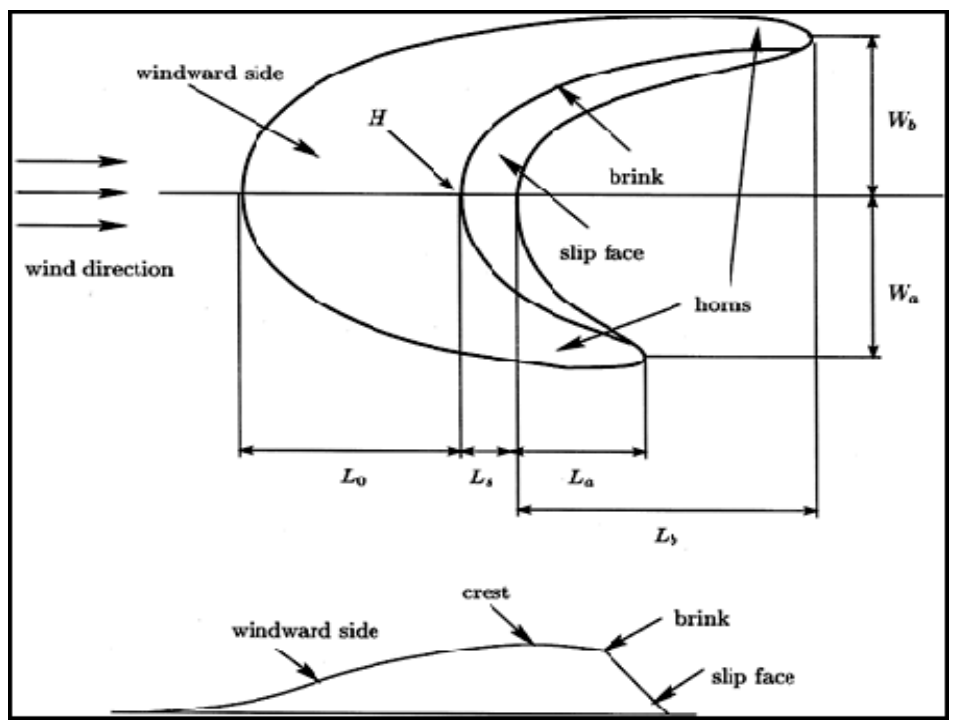

Figure 3. Sketch of a morphometric parameters of barchan dunes (Sauermann et all, 2003)

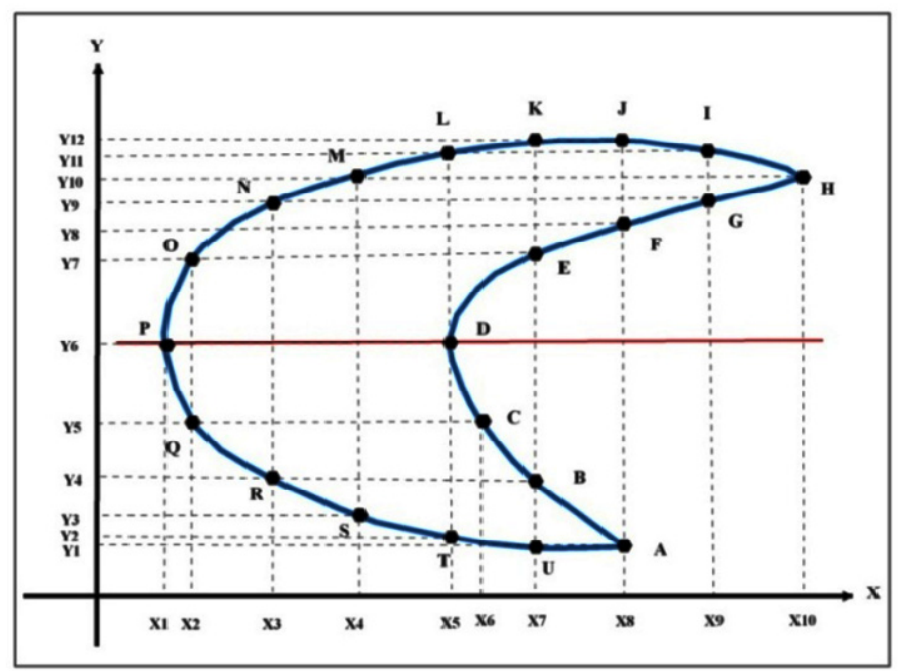

Figure 4. Measurement method of barchan perimeter and area; $\mathrm{A}(\mathrm{x} 8, \mathrm{y} 1), \mathrm{B}(\mathrm{x} 7, \mathrm{y} 4), \mathrm{C}(\mathrm{x} 6 . \mathrm{y} 5)$, and so on

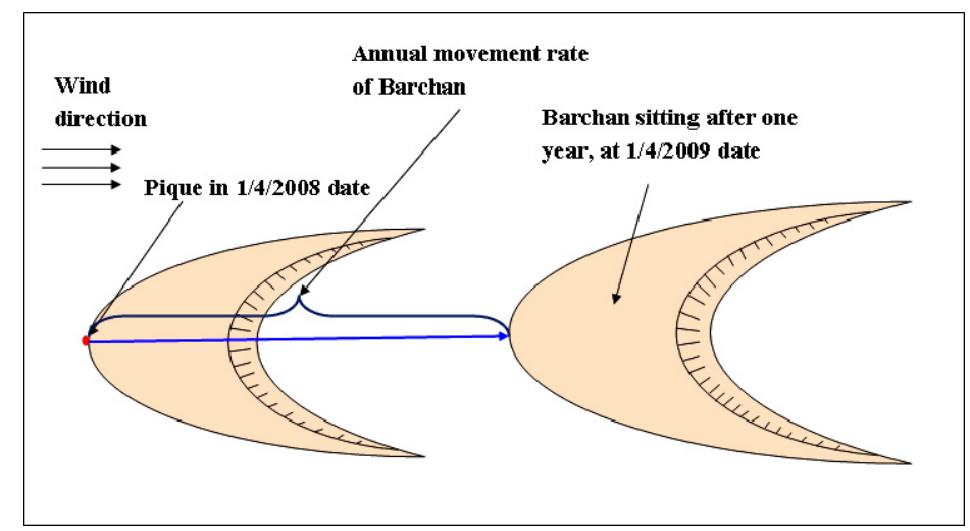

Figure 5. Measurement method of barchans movement rate 


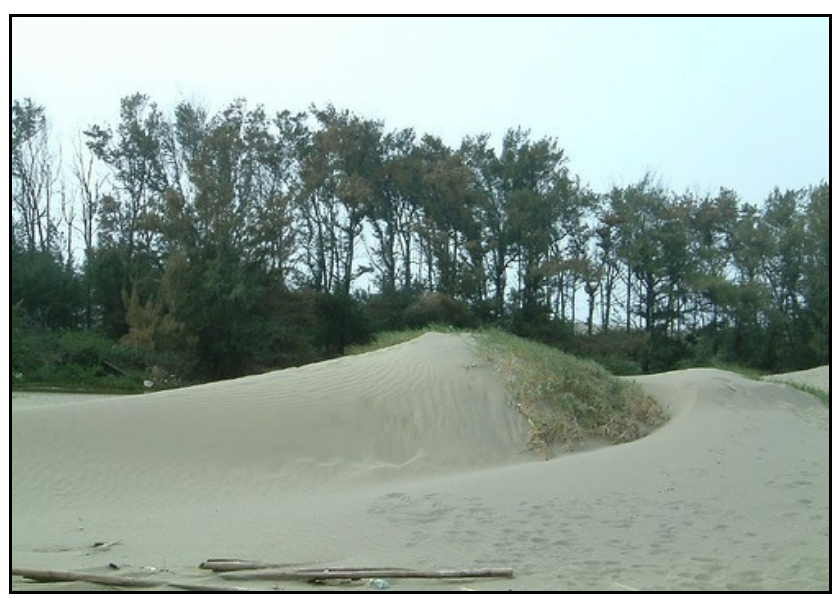

Figure 6. Barchan dunes in study area and their effect on desertification and disturbance of human infrastructure

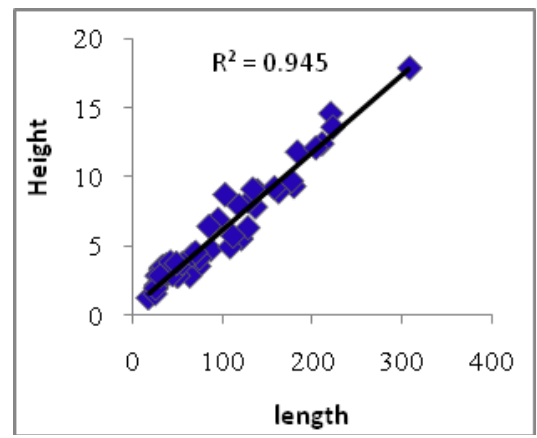

A

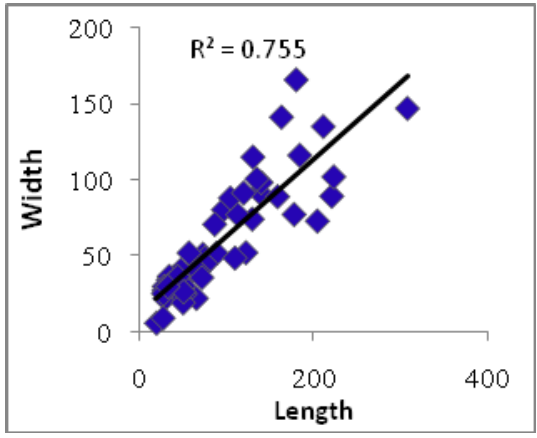

B

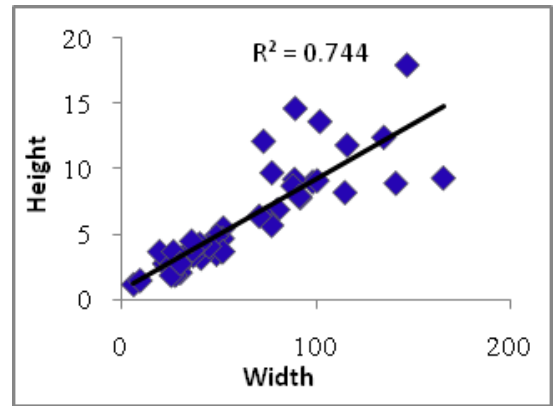

C

Figure 7. Relationships between morphometric parameters of studied barchan dune; A: Relationship between height and length, B: Relationship between width and length, C: Relationship between height and width 


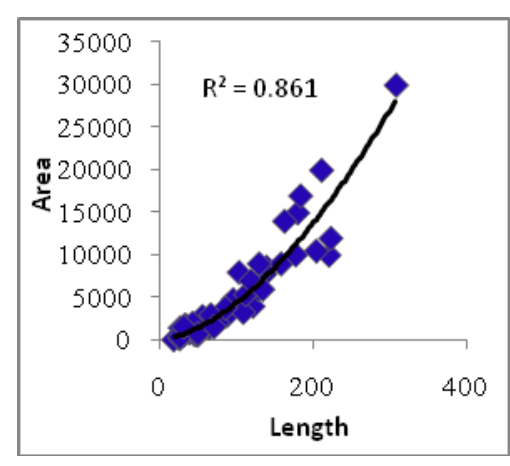

A

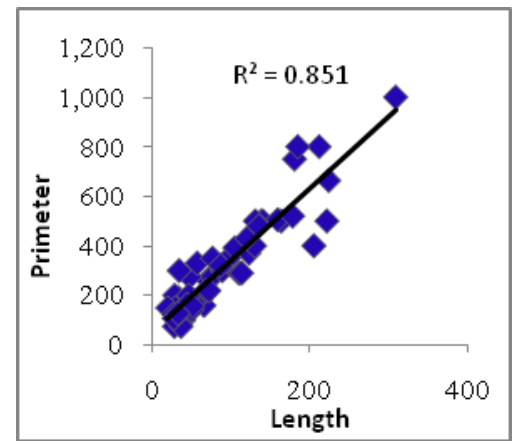

$\mathrm{C}$

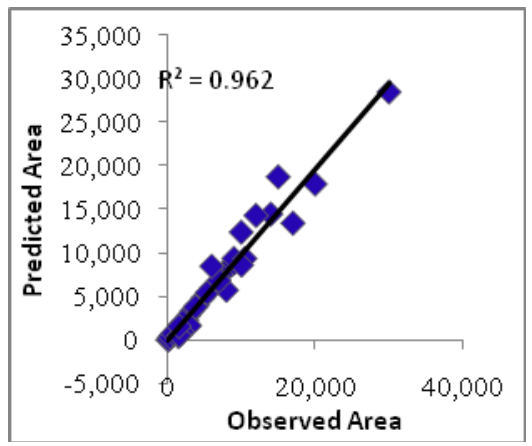

E

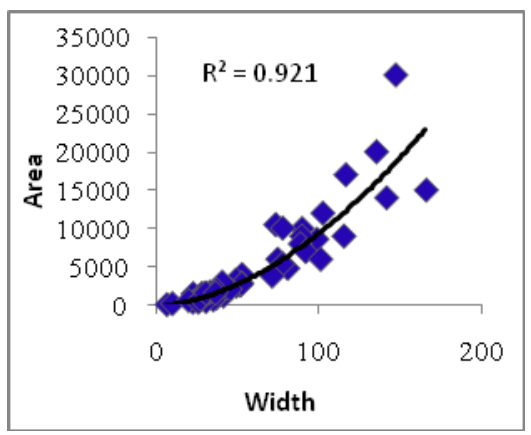

B

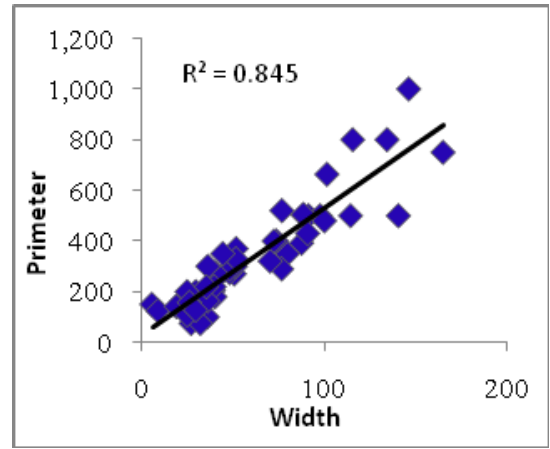

$\mathrm{D}$

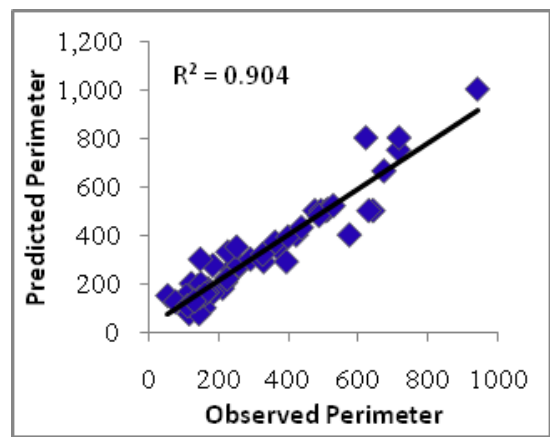

F

Figure 8. Relationships between plane geometry and morphometric parameters of studied barchan dunes; A:

Relationship between area and length, B: Relationship between area and width, C: Relationship between perimeter and length, D: Relationship between perimeter and width, E: Relationship between predicted area and observed area, F: Relationship between predicted perimeter and observed predicted 


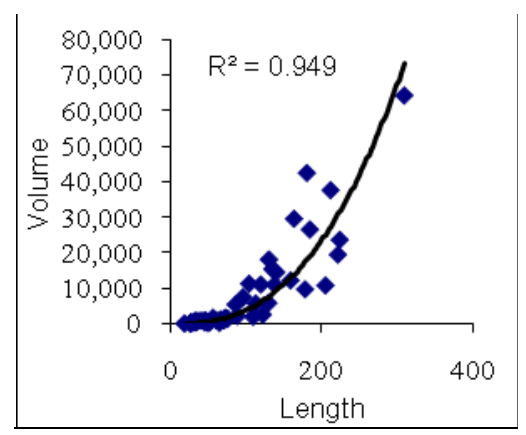

A

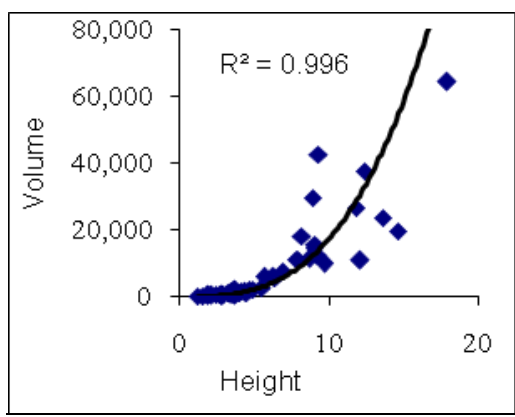

$\mathrm{C}$

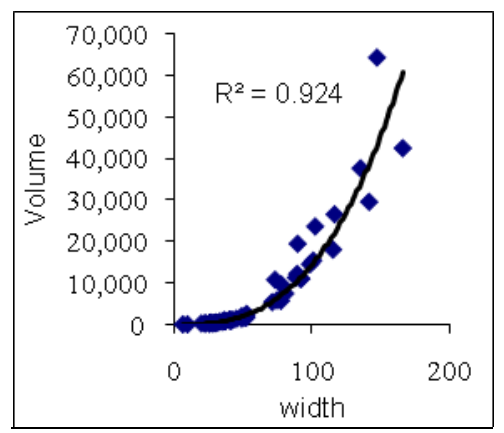

B

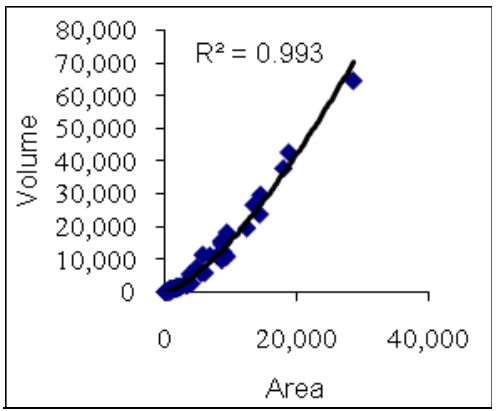

D

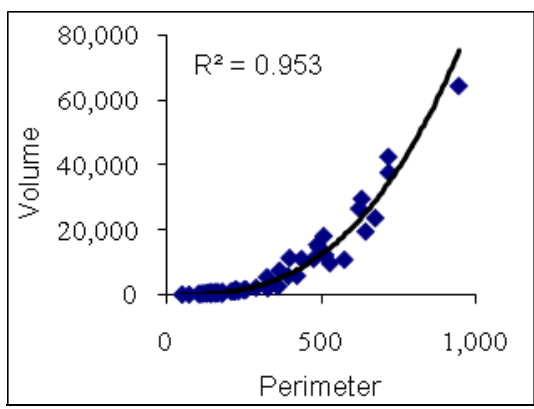

E

Figure 9. Relationships between volume and morphometric parameters of studied barchan dunes; A: Relationship between volume and length, B: Relationship between volume and width, C: Relationship between volume and height, D: Relationship between volume and area, E: Relationship between volume and perimeter 


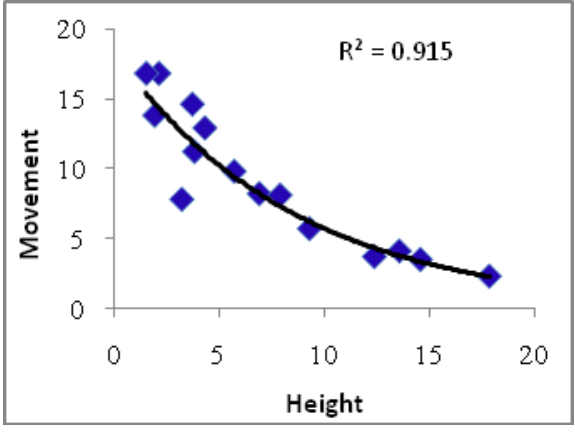

A

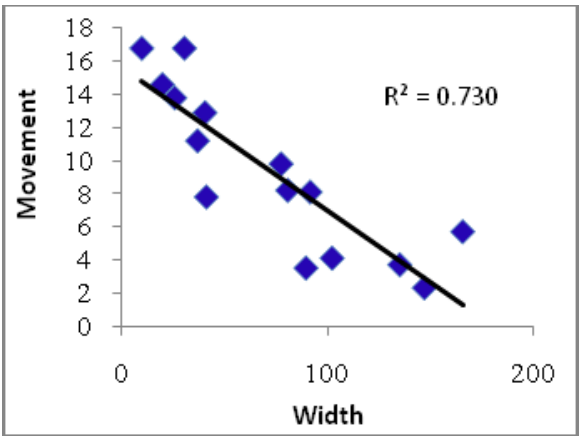

C

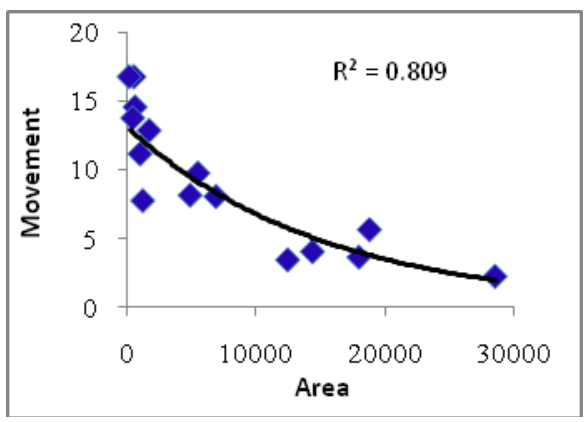

E

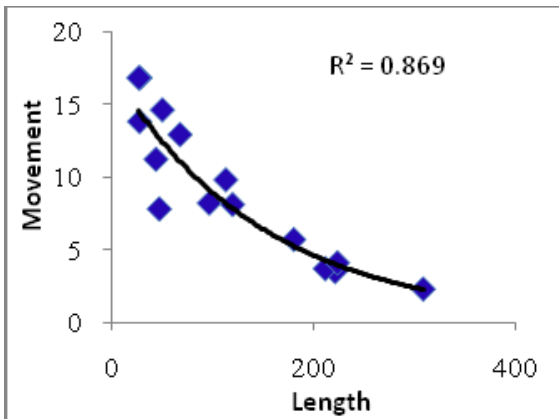

B

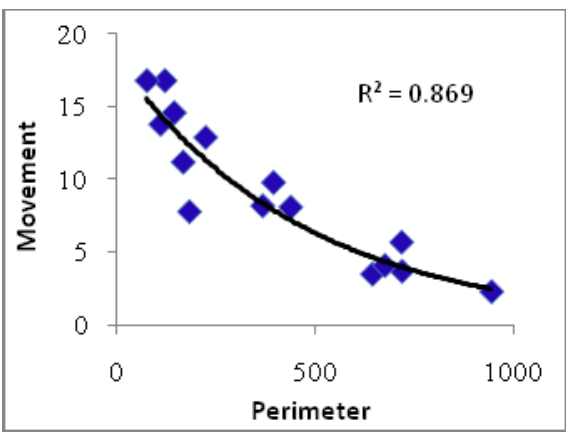

D

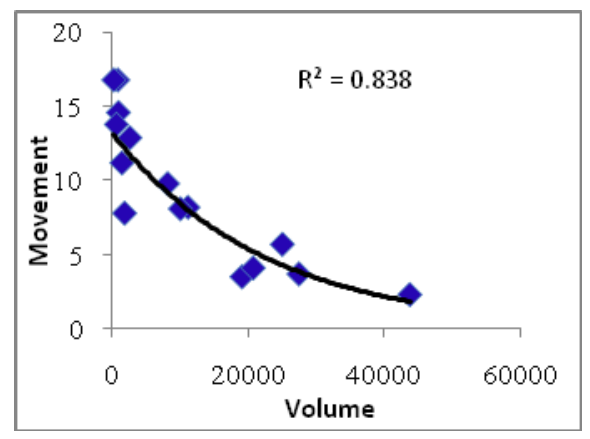

$\mathrm{F}$

Figure 10. Relationships between movement rate and morphological parameters of studied barchan dunes; A: Relationship between movement and height, B: Relationship between movement and length, C: Relationship between movement and width, D: Relationship between movement and perimeter, E: Relationship between movement and area, F: Relationship between movement and volume 